Luxembourg Income Study Working Paper No. 292

\author{
EXPLORING THE SUBNATIONAL DIMENSION \\ OF INCOME INEQUALITY: AN ANALYSIS \\ OF THE RELATIONSHIP BETWEEN INEQUALITY AND \\ Electoral Turnout in the Developed Countries
}

Vincent A. Mahler

January 2002 


\title{
EXPLORING THE SUBNATIONAL DIMENSION OF INCOME INEQUALITY: AN ANALYSIS OF THE RELATIONSHIP BETWEEN INEQUALITY AND ELECTORAL TURNOUT IN THE DEVELOPED COUNTRIES
}

\author{
Vincent A. Mahler \\ Loyola University Chicago
}

Acknowledgements: Many debts have been incurred in writing this paper. Above all, I would like to thank David K. Jesuit, Project Manager and Senior Research Associate of the Luxembourg Income Study, for graciously responding to a seemingly endless stream of questions and requests for data. I would also like to thank Angela Hinton-Andersson, Vincent Hildebrand and several anonymous reviewers for their comments; and Patrick Van Inwegen and Penelope Safioleas for research assistance. The research for this paper was supported in part by a Research Leave from Loyola University Chicago and an IRISS (Integrated Research Infrastructure in the Social Sciences) grant from the Center for Population, Poverty and Public Policy Studies/ International Networks for Studies in Technology, Environment, Alternatives, Development (CEPS/INSTEAD) in Differdange, Luxembourg. 


\begin{abstract}
This paper offers an exploratory analysis of the subnational dimension of income inequality, using data from the Luxembourg Income Study. The paper undertakes two basic tasks. First, it describes the results of calculations on household-level income data that produce indicators of intra- and inter-household inequality for 191 regions in 12 developed countries for the late 1980s and early 1990s, and for 149 regions in 8 countries for the mid-1990s. Second, the paper demonstrates the value of regional analysis by re-examining the relationship between electoral turnout and income inequality, an important substantive issue which has heretofore been explored almost entirely at the national or individual level but upon which regional-level analysis can shed valuable light.
\end{abstract}


In recent years, a large body of scholarly research in the field of comparative political economy has explored the causes and consequences of cross-national variation in income inequality in the developed world (see, e.g., Pampel and Williamson, 1989; Gottschalk and Smeeding 1997; Cline, 1997; Wallerstein, 1999; and Gustafsson and Johansson, 1999). In virtually all of this work, data have been aggregated at the level of the nation-state.

Although national-level analysis has much to recommend it, it can also be somewhat misleading. This is particularly true for variables like income distribution, where the focus is not on central tendency but rather on dispersion. One problem is that large aggregates like nations often encompass a good deal of regional variance in inter-household income inequality, variance that is averaged out in national-level summary figures. A second problem arises from the fact that national-level data fail to distinguish inequality within regions from variance in median income across regions, the sources of which may be very different. These concerns would be troubling even if all national units were the same size, but they are exacerbated when units vary greatly in population size - as is manifestly the case for the nations of the developed world.

Despite these concerns, there has until recently been little alternative to measuring income distribution at the level of the nation-state. Comparable data on income inequality have long been scarce even at the national level, and subnational-level data have been, for all but a tiny handful of countries, simply unavailable. Fortunately, the situation has improved dramatically during the last decade through the efforts of the Luxembourg Income Study (LIS), a major international effort to assemble household-level data on income distribution that are much more comprehensive and detailed than the best available data of even a few years ago. For present purposes, the key advantage of the LIS is that it allows one to identify the geographical region in a country within which respondents to national income surveys reside.

The aim of this paper is to offer an exploratory empirical analysis of the subnational dimension of income inequality. More specifically, the paper will undertake two basic tasks. First, it will describe the results of a series of calculations on LIS household-level income data that produce regional-level indicators of income inequality for nearly 200 regions in a dozen 
developed countries. It is hoped that these data will be of interest to researchers both in their own right and as a vehicle for extending the analysis of the causes and consequences of income inequality in a valuable new direction. Second, the paper will demonstrate the practical value of subnational analysis with reference to a longstanding substantive research question, the relationship between income inequality and electoral turnout, which has heretofore been examined largely at the national or individual levels. As will be shown, subnational analysis can shed valuable light on this topic, allowing a more detailed and nuanced examination than would otherwise be the case and addressing questions that studies at other levels leave unanswered.

\section{INCOME INEQUALITY AT THE REGIONAL LEVEL}

a. Measurement Issues. As has been indicated, the source of data on household income employed in this paper is the Luxembourg Income Study. Essentially, the task undertaken in the LIS project has been to organize raw data from income surveys conducted by various national statistical agencies in such a way as to permit meaningful cross-national comparisons. ${ }^{1}$ The LIS presently incorporates surveys from over two dozen countries, in many cases for several points in time. It offers data on numerous individual sources of income from the public and private sectors, as well as on household size and composition.

By offering detailed micro-data on household income, the LIS allows researchers to construct measures of income inequality that are much more consistent definitionally than has previously been the case. ${ }^{2}$ For example, LIS data permit consistent adjustments for household size, something that has not been true of most earlier sources of data on income distribution. In practice, a common adjustment is to divide total household income by the square root of household size, which reflects economies of scale in supporting progressively larger households, weighting the resultant value by the number of persons in the household (Atkinson et al., 1995: 18-21). This is the method that will be employed in the analysis that follows to produce the variable "adjusted household income." 3

LIS data also allow one to examine a number of different sources of income. In this paper, the focus will be on what the LIS terms "disposable personal income," which includes all 
income from all sources, net of income taxes and mandatory social insurance contributions (Atkinson et al., 1995: 30-34, 39-41). More specifically, this definition includes such private sources of income as wages and salaries; income from self-employment; interest, rents and property income received on a regular basis; occupational pensions; regular inter-household cash transfers; and court-ordered payments such as alimony and child support. Also included is income from public benefit programs, including sick pay; disability pay; retirement benefits; child or family allowances; unemployment compensation; maternity pay; military, veterans' or war benefits; and means-tested public assistance.

The most important LIS variables for purposes of this paper are those that place households within geographical regions in their country. ${ }^{4}$ The exact nature of a country's geographical breakdown is determined by national statistical authorities. In the case of federal countries, such as Australia, Canada, Germany and the United States, LIS regional units are the constituent states or provinces. ${ }^{5}$ In most other countries, they reflect longstanding distinctions that are of cultural, electoral and administrative significance.

As has been indicated, in exploring the regional dimension of income distribution it is important to distinguish between intra- and inter-regional inequality. In examining intra-regional inequality, a key measurement issue has to do with the variable or variables used to summarize the degree of inequality among households within a region. One commonly employed indicator is the percentile ratio, which expresses the ratio of household incomes, adjusted for household size, at various percentile points on the income scale. The analysis that follows will focus on the ratio of the income of a household at the 90th percentile to that of one at the 10th percentile. Another widely used measure is the Gini index, which offers a summary indication of the overall degree of household income inequality in a region, again adjusted for household size. Both of these measures of inequality will be reported in the tables that follow. ${ }^{6}$

In comparing inter-regional inequality, a useful indicator is the ratio of the median income of a given region to the median income of the country in which it is located. For example, the median adjusted household income across the entire United States in 1994, as 
calculated from LIS micro-data, was $\$ 18,076$. At the state level, median adjusted household income ranged from a high of $\$ 23,785$ in Connecticut to a low of $\$ 14,492$ in Mississippi. The figure for Connecticut was thus 1.32 times that of the U.S. as a whole $(\$ 23,785 / \$ 18,076)$, while that for Mississippi was 0.80 times that of the U.S. as a whole $(\$ 14,492 / \$ 18,076)$. In a similar manner, it is possible to calculate regional/national income ratios for all countries for which LIS income data are available. ${ }^{7}$

LIS data are available for several "Waves," each of which includes income surveys conducted within a few years of one another. The emphasis in this paper is on the two most recent LIS Waves: Wave III, covering the late 1980s and early 1990s, for which data are available for 191 regions in 12 developed countries; and Wave IV, covering the mid-1990s, which is in progress but for which data are currently available for 149 regions in 8 countries. ${ }^{8}$

b. An Overview of the Data. Table 1 presents the data on 90/10 percentile ratios, Gini indexes, and regional/national median income ratios that have been described in the preceding section. ${ }^{9}$ In offering these data, it is useful to note any patterns in the distribution of income aggregated at the subnational level. A good general sense of distributions of this sort is provided by the boxand-whiskers plot, an exploratory data analysis tool developed by John Tukey (1977: 27-56). In a box-and-whiskers plot, the "box" represents the range of values that fall between the 25 th and 75th percentiles. Values above or below the middle two quartiles are indicated by "whiskers" extending from the box, which encompass cases that fall within 1.5 box lengths from the upper or lower edges of the box. (If no case falls as far as 1.5 box lengths from the upper or lower edge of the box, the whiskers extend to the highest or lowest case. $)^{10}$

As has been suggested, national-level inequality can profitably be decomposed into within- and between-region components. ${ }^{11}$ Intra-regional variation will be discussed first. The patterns are evident in Figures 1 and 2, which depict 90/10 regional percentile ratios for LIS Waves III and IV. (Patterns for Gini indexes are similar.) As can be seen, the box-and-whiskers 
plots indicate substantial variation in the extent of inequality within regions-variance that is, of course, averaged out when national-level figures are calculated.

In the plots, the placement of boxes and whiskers in the vertical dimension is anchored by the median level of within-region inequality in a country. As the Wave III data in Figure $\mathbf{1}$ indicate, the U.S. had by far the highest median level of intra-regional inequality, followed distantly by the U.K. and Australia. The fact that income is more unequally distributed in the U.S. than in other developed countries is, of course, well known. What is not as well known is that national-level figures for the U.S. mask enormous variation in internal inequality from state to state. ${ }^{12}$ This is demonstrated graphically by the fact that the box and the whiskers in the U.S. plot are each far wider than those of any other country. At the low end of this wide distribution, the most egalitarian U.S. states do not demonstrate more internal inequality than is typical of regions in many other countries. The most inegalitarian U.S. states, however, are marked by intra-regional income inequality far beyond that in even the most inegalitarian regions in other developed countries. As can be seen in Table 1, 32 Wave III regions had 90/10 ratios greater than 5.00. No fewer than 29 of these were U.S. states. (The others were Corsica, Sicily and Greater London.)

The pattern is similar for the regions for which Wave IV data are currently available. Once again, the U.S. has the highest median 90/10 ratio, and once again it is marked by a wider range across regions than any other country. As can be seen, the range of intra-regional inequality for the U.S. has narrowed slightly since LIS Wave III. The reason is not, however, that inequality has become less pronounced. Instead, by the mid-1990s the most egalitarian Wave III regions had become somewhat less egalitarian while the least egalitarian regions had remained essentially the same - a pattern in evidence in several other countries as well. For example, the $90 / 10$ ratio represented by the lower whisker for the U.S. rose from about 3.0 to nearly 4.0, while that of Canada rose from slightly over 2.5 to about 3.5 .

The other component of national-level income inequality is the distribution of income across regions. Figures $\mathbf{3}$ and $\mathbf{4}$ offer box-and-whiskers plots of the inter-regional distribution of 
adjusted household income for the countries covered in LIS Waves III and IV. As can be seen, there is substantial variation in regional/national ratios across the Wave III regions. The country with the greatest inter-regional dispersion in median household income is Italy, whose box extends from approximately $120 \%$ to $80 \%$ of the Italian median, and whose whiskers extend a considerable distance beyond its box. This dispersion reflects the dramatic income differences between Northern and Southern Italy_-differences that have, in fact, long dominated Italian politics. Relatively wide ranges of inter-regional variance are also evident in Spain, the U.S. and Canada. On the other hand, a number of countries, notably Belgium, Finland and Sweden, demonstrate very little inter-regional variation in median income. In the Swedish case, for example, the median adjusted household income of the richest region, Stockholm, is only 1.10 times the national median, while that of the poorest, South, is 0.96 times the national median.

A similar pattern is in evidence for Wave IV regions. As can be seen, the widest interregional range by far is again that of Italy. Interestingly, the next widest box is found in Germany, whose Wave III range was much narrower. The reason for this is the inclusion in LIS Wave IV of the former German Democratic Republic Länder, which were not included in Wave III-all of whose adjusted median household incomes are well below the German median. Relatively wide inter-regional dispersion is also in evidence for Canada and the U.S.

Since it has been so widely reported that income inequality has been growing over the last decade in the developed world, it is useful to offer a more systematic assessment of any trends in the regional-level figures that have been computed for this paper. Of the 141 regions that can be directly compared, 90/10 percentile ratios increased in 90 and Gini indexes in 99, indicating that there is indeed a general, if not universal, trend toward greater within-regional inequality between LIS Waves III and IV. ${ }^{13}$

In contrast to the increase in within-region inequality, between-region inequality actually decreased slightly between Waves III and IV. The standard deviation of regional/national median income ratios across each country's regions decreased in 6 of the 8 countries for which regional data are available for both Waves. Although regionalism has become more prominent 
as a political issue in many countries, this does not appear to be reflective of a general increase in inter-regional income inequality comparable to the increase in intra-regional inequality.

\section{APPLYING REGIONAL-LEVEL ANALYSIS TO A SUBSTANTIVE PROBLEM}

a. Political Sources of Inequality. Because regional data on income inequality have not been widely available, this paper has devoted a good deal of attention to measurement issues and has described patterns in the data in more than the usual detail. However, introducing new dataeven very interesting data — can take us only so far. The value of the data described above will be much enhanced if it can be demonstrated that analysis at the subnational level offers insights into important substantive questions, complementing findings based exclusively on analysis at the national level. In this section, the regional-level data on income inequality described in the preceding section will be used to re-examine a longstanding research topic in the cross-national literature that has heretofore been explored primarily at the national level, the relationship between income inequality and turnout in national elections.

The basic arguments are straightforward. It is frequently claimed that low turnout in elections tends to be concentrated among groups that have the least stake in the political system and are thus the most difficult to mobilize_-among whom low-income groups are disproportionately represented (Lijphart, 1997; Verba et al., 1978). Without the political mobilization represented by voting, it is argued, these groups are less able to exert pressure to enact policies that benefit them, such as education and housing programs, progressive taxes, social transfers, and favorable regulatory and economic development policies—which will in turn be reflected in a less egalitarian distribution of income. On the other hand, to the extent that turnout is high, benefits are likely to be proportionally allocated among income groups, resulting in a more egalitarian distribution of income than that generated by the market. As put by Lijphart (1997: 2-3, 5), summarizing a wide range of empirical studies, "low voter turnout means unequal and socioeconomically biased turnout. . . Who votes, and who doesn't, has important consequences for who gets elected and for the content of public policies." ${ }^{\text {"14 }}$ The reason, in the 
words of Key (1949: 527), is simple: "The blunt truth is that politicians and officials are under no compulsion to pay much heed to classes and groups of citizens that do not vote."

Clearly, the relationship between electoral turnout and income inequality is of considerable interest from a theoretical perspective: the linkage between political participation and economic well-being has long been a central concern of the discipline of political science (see, e.g., Dahl, 1971: 81-104). The relationship between turnout and inequality also stands out empirically because the developed democracies vary so widely on both: there is nearly a 2-to-1 ratio across the developed countries between the highest and lowest national values of both the 90/10 percentile ratio of household income inequality and the proportion of eligible voters who participate in national elections, wider than the range of many other much-studied variables.

In light of its importance, there has been surprisingly little cross-national empirical work on the relationship between turnout and inequality. Certainly, studies have worked on the edges of the topic. There have, for example, been a number of assessments of the sources of crossnational variance in turnout, with many scholars emphasizing the importance of institutional factors, such as whether voter registration is automatic or whether a country's electoral system operates through single- or multi-member districts (Powell, 1986; Jackman, 1987; Wolfinger et al., 1990; Jackman and Miller, 1995; Franklin, 1996). Exploring the institutional sources of variance in turnout is not, however, the same as exploring its relationship to income inequality. Similarly, there have been a number of cross-national studies assessing the relationship between electoral turnout and social benefit expenditures, with the implicit assumption that large expenditures on social programs will in turn be associated with a more egalitarian distribution of income (Pampel and Williamson, 1989; Hicks and Swank, 1992; Crepaz, 1998). However, the strength of the latter relationship varies widely across countries, in part because the largest social benefit programs in many countries tend to be only mildly redistributive across income (if not necessarily age) groups, and in part because social benefits are only one of the ways in which governments redistribute market income. When all is said and done, very few empirical studies have focused directly on the relationship between electoral turnout and income inequality across 
a reasonably wide range of developed countries.

Why has so little attention been devoted to a relationship that would appear to be both important and interesting? A major reason has been, quite simply, a lack of data. The problem has not been with data on electoral turnout, which have long been readily available at various levels of aggregation. Instead, the limiting factor has been a lack of data on income inequality. In particular, annual time series on household income inequality are available for only a tiny handful of countries, making this one of the few areas of cross-national research that cannot make use of the large pooled cross-sectional/time series data sets that have become commonplace in the field. ${ }^{15}$ As a result, researchers confront directly the hard fact that the number of developed democracies is very small - a fact which is manifested statistically in a severe shortage of degrees of freedom that makes multivariate analysis difficult. To make matters worse, small-n studies of both income inequality and turnout tend to be dominated by individual cases - particularly the United States, which has the most inegalitarian distribution of income and the lowest electoral turnout of any major developed country. "American exceptionalism" has, in fact, been a continual theme of those studying the political sources of income inequality (see, e.g., Skocpol and Amenta, 1989), while studies of electoral turnout have invariably struggled with the "deviant” U.S. case (see, e.g., Powell, 1986; Jackman, 1987; Jackman and Miller, 1995). ${ }^{16}$

One way of addressing these concerns is to supplement national-level analysis with analysis at the level of regions within nations-something that the subnational data reported in the first part of this paper make possible for the first time for a reasonably large number of countries. The most straightforward reason for examining regions is that analysis at this level offers a great many more cases than national-level analysis-for the countries examined in this paper, more than ten times as many. Beyond this, regional-level data provide a much more finely discriminated measure of both turnout and inequality than do national-level figures, which often represent averages of very diverse regions. Finally, as discussed earlier, regional statistics permit us to discriminate between inequality within and across regions, a distinction that is lost at 
the national level.

At this point, an example is probably in order. As a baseline, we begin with an analysis at the national level. ${ }^{17}$ When national-level turnout in the general election in the same year as or immediately prior to the point in time for which income inequality is measured is related to the national-level 90/10 percentile ratio and Gini index of adjusted household income for 16 Wave III countries in an Ordinary Least Squares (OLS) regression, we find that electoral turnout is indeed negatively related to both variables: $\mathrm{b}=-.04$, beta weight $=-.522, \mathrm{t}=-2.29, \mathrm{p}=.038$; and $\mathrm{b}=-.002$, beta weight $=-.460, \mathrm{t}=-1.94, \mathrm{p}=.073$ respectively. ${ }^{18}$ The relationship is, however, affected to a substantial degree by the single case of the United States, whose electoral turnout is the lowest of any of the 16 countries and whose income inequality is the highest. (See Figure 5.) When the U.S. case is removed, the relationships, while still negative, are no longer statistically significant.

At this point, studies operating at the national level enter something of a blind alley. Eliminating the U.S. as an "influential case" is a possibility, but this seems a rather extreme solution. For one thing, U.S. values are not so atypical as to constitute highly influential cases in the technical sense, as measured by standard criteria such as Cook's Distance: Cook's D for the U.S. is only slightly above the conventional criterion of 1.0 in the first equation and below it in the second (Cook and Weisberg, 1995: 358). Beyond this, an analysis with fewer than 20 cases offers little opportunity to explore competing explanations for cross-national variance in income inequality in a multivariate model.

As has been suggested, one way of moving forward is to conduct the above analysis at the level of geographical regions within nations. Certainly, if findings at the subnational level were inconsistent with those at the national level, the latter would be called into question. On the other hand, a strong relationship at the regional level would offer confirmation of the somewhat inconclusive national-level findings.

Again, it is useful to begin with a bivariate analysis. As it happens, the structured nature of the regional data set is such that is desirable to account for national-level effects in a fixed 
effects model. (A sign that national-level effects matter is that equations without dummies are marked by a moderate amount of first-order autocorrelation or fall into the indeterminate range.) ${ }^{19}$ Each equation thus includes D-1 dummy variables representing the countries in the analysis. These equations are the basis for the figures that are reported in table 3.

As can be seen, across 184 Wave III regions (all of the LIS regions discussed in the first section except those in Sweden, for which regional-level turnout data consistent with LIS boundaries are unavailable) electoral turnout is significantly negatively related at the $\mathrm{p}=.001$ level to both the 90/10 percentile ratio and the Gini index of adjusted disposable household income. There is also evidence of a (much weaker) positive relationship across Wave III regions between electoral turnout and the regional/national median income ratio. Broadly similar findings are in evidence for 96 Wave IV countries. ${ }^{20}$ Again, electoral turnout is negatively related to the 90/10 ratio and (more weakly) the Gini index of household income inequality, and positively related to the regional/national median income ratio.

Clearly, electoral turnout is not the only variable of interest in explaining cross-national variance in income inequality. As has been indicated, a major advantage of regional-level data is that it makes it much easier to conduct a multivariate analysis that includes other explanatory variables. One longstanding theme in the literature looks to the partisan orientation of national legislatures. The basic thesis is simple: that leftist parties are more likely than rightist parties to take into account the needs of low-income groups in enacting tax law, formulating regulatory policies, allocating government consumption expenditures and apportioning social benefits (Hicks and Swank, 1992; Cusack, 1997; Crepaz, 1998). One indicator of the partisan orientation of a given region, which we will call "left party balance," is the proportion of its seats in the national legislature that are controlled by leftist political parties less the proportion controlled by rightist parties, which results in a measure ranging from -100 (all seats held by rightist parties) to +100 (all seats held by leftist parties). The party classification is that of Castles and Mair (1982), which is widely used in the literature. ${ }^{21}$ 
Another important explanatory tradition argues that cross-national variation in income inequality is the product not of political but rather of sociological factors, particularly those associated with family structure. One of the most frequently cited such factors is the proportion of all households that are headed by unmarried females, which are said to be under severe pressure not only socially and psychologically but also in their ability to function as an economic unit (see, for a cross-national assessment, Kamerman, 1995). As it happens, it is possible to calculate from LIS income surveys the proportion of all households in a given region that are headed by single females, a number that ranges from lows of around 10 percent in several Italian regions to highs of over 35 percent in several Danish and U.S. regions.

The findings of the multivariate analysis described above are reported in table 3. As can be seen, when these two additional variables are included in equations for Wave III regions, we find that electoral turnout continues to be the strongest explanatory variable, related at the $\mathrm{p}<.01$ level to both the 90/10 ratio and Gini index of intra-regional inequality. In addition, the proportion of all households in a region headed by unmarried females is significantly positively related to the Gini index of within-region inequality (but not the 90/10 ratio): it does appear that, as hypothesized, family structure has an independent effect on income distribution. On the other hand, the relative prominence of leftist parties in a region's delegation to the national legislature is not significantly related to either the $90 / 10$ ratio or the Gini index.

A comparable multivariate analysis for Wave III regions seeks to explain cross-regional variance in the regional/national median income ratio. As can be seen, our left party balance variable, which was unrelated to our indicators of intra-regional income inequality, is significantly related (in a negative direction) to the regional/national median income ratio (see table 3).

Findings for Wave IV regions are broadly similar to those for Wave III. ${ }^{22}$ As can be seen in table 3, electoral turnout is significantly negatively related to the $90 / 10$ ratio in our multivariate model, while its relationship to the Gini index, while not nearly as strong, is in the expected direction. Again, the proportion of all households that are headed by single females is 
positively related to both of our indicators of income inequality. In contrast to Wave III, however, countries' regional/national median income ratio is significantly related in a positive direction to electoral turnout, but not to our left party balance variable.

As was shown earlier, the United States is an unusual case with respect to both income inequality and electoral turnout. With national-level data, there is little one can do to explore this further, other than to characterize the U.S. as "exceptional" or "deviant" in these respects in comparison to other developed countries and perhaps eliminate it from further consideration for that reason. With regional data, however, it is possible to examine the relationship between electoral turnout and income inequality across the U.S. states, which holds constant any effect unique to that country's political or economic history.

Analyses similar to those for all regions have accordingly been conducted for the U.S. states and the District of Columbia. ${ }^{23}$ The findings are described in table 4. As can be seen, findings for U.S. states generally parallel those for the entire Wave III and IV regional data sets. For example, electoral turnout is again consistently negatively related to the 90/10 ratio and Gini index of household income inequality. Similarly, the proportion of households headed by single females is again generally positively related to income inequality, while our left party balance variable is negatively related or unrelated. Finally, neither electoral turnout, the proportion of all households headed by single females, nor the left party balance is significantly related in either direction to the regional/national median income ratio.

In sum, regional-level analysis does a good deal to reinforce the necessarily limited national-level findings linking electoral turnout and income inequality. Several separate regional-level analyses not only support the basic national-level conclusions but also offer a considerably more nuanced picture of the relationship between turnout and inequality by controlling for other relevant variables, distinguishing between inter- and intra-regional inequality, and looking separately at regional variance across the U.S. states. 
b. Levels of Analysis: A Closer Look. In assessing these findings, it is useful to explore more closely the precise mechanisms that underlie the observed regional-level relationship between electoral turnout and income inequality. As has been indicated, the national-level literature on the topic has focused on the distributive impact of taxes and income transfers. With some exceptions, however, the major redistributive tax and transfer policies in the developed world operate at the national level rather than at the level of regions within nations, leaving one to wonder why national-level relationships should be echoed at the regional level.

In fact, redistributive policies in a number of areas can and do operate at the regional level. This is particularly true in such areas as education, job training, housing, urban renewal and rural development, but regions also frequently play at least some role in such traditionally national policy areas as health care and social insurance. Activities in these areas are financed both by direct taxes at the regional level and by block grants to regional units from the central government. Although the latter invariably come with strings attached, they also ordinarily allow for a good deal of local discretion.

Regions play the most prominent role in the area of education. In all but three of the nine LIS countries for which functional breakdowns are available in the IMF's Government Finance Statistics Yearbook (1997), regional (or, where regional figures are unavailable, local) expenditures for education exceed those of the central government. In a number of countries, regional dominance is very substantial. In Germany, for example, some $90 \%$ of all educational spending occurs at the subnational level; in Canada and the U.S. the comparable figure is over $75 \%$, and in the U.K. and Spain it is over 60\%. A similar picture is in evidence for the IMF's category "housing and community amenities": in seven of the nine countries for which functional breakdowns are available, more expenditures in this area were allocated by regional or local governments than by the central government. Regions are somewhat less prominent in the area of health care, but even here they play an important supplementary role. In Canada, for example, provincial governments accounted for some three quarters of public health care expenditures, in Australia about half, in the U.S. about a third, and in the U.K. about a fifth. 
Even in the IMF's functional area "social security and welfare," in which central governments are most dominant, regions often play a role in supplementing central government efforts: on average, across the countries for which breakdowns are available, subnational governments accounted for about a fifth of total public expenditures in this area. In all of these areas, regional policies are the product of a complex interplay between national and regional policy-makers in which national politicians typically act both as participants in national-level decision-making and as representatives of regional interests.

In addition to direct expenditures, regions often participate in administering nationally funded programs, resulting in at least some regional variation in eligibility determination and the application of general rules to particular cases. In Germany, for example, Land governments employ some $90 \%$ of all civil servants, and thus play a prominent role in administering nearly the entire range of domestic policies. Similarly, U.S. states participate in administering several important federal programs, including the U.S. Social Security Administration's disability program and public assistance grants to low-income households, while the autonomy of Canadian provinces in a number of traditionally national social policy areas was enhanced in the 1990s with the implementation of the Canada Health and Social Transfer.

Finally, regional representatives are often deeply involved in formulating tax incentives, subsidies and regulations affecting private enterprises-invariably to the benefit of some income groups and at the expense of others. The distributive effect of such policies is notoriously difficult to measure, since benefits appear in household accounts as market income rather than income from the public sector. There is, however, every reason to believe that substantial income redistribution - in various directions — occurs as a result of public efforts to support or regulate the private sector and that regions play a prominent role in formulating and administering such policies.

In sum, it is plausible that political participation at the regional level will have an effect on income inequality distinct from that at the national level. Specifically, political representatives from high-turnout regions, who face an electorate that includes a large number of 
politically mobilized low-income constituents, can be expected to pursue policies that benefit those constituents. On the other hand, representatives from regions with relatively few politically mobilized low-income households are less likely to pursue policy objectives favoring those groups. Regional dynamics of this sort are reinforced by the fact that the regions examined in this paper generally have well-established political identities-identities that have often been enhanced over the last two decades as a result of the institutional decentralization that has occurred in much of the developed world, even in such traditionally highly centralized unitary systems as France, Spain and Italy.

a. A Fuller Model. In more fully exploring the relationship between electoral turnout and income inequality, it is desirable to extend the analysis backward by considering the sources of cross-national variance in electoral turnout - a topic that is, as mentioned earlier, the subject of a large literature. A key question is the extent to which turnout is affected by countries' electoral institutions (Powell, 1986; Jackman, 1987; Wolfinger, 1990). Scholars have proposed a number of national-level institutional variables that are said to explain cross-national variance in electoral turnout. Three such variables have been especially prominent in the literature. The first measures the degree to which elections in a country are "nationally competitive," the key distinction being between single member district electoral systems and various forms of proportional representation (PR). The central idea is that "with proportional representation from the nation as a whole or from large districts, the parties have an incentive to mobilize everywhere. With single-member districts, some areas [i.e., "safe seats"] may be written off as hopeless" (Powell, 1986: 21). In measuring this dimension, we will employ Powell's four-value scale ranging from national-level PR systems, through large-district PR systems, through smalldistrict PR systems, to single member constituencies (Powell, 1986: 38).

A second institutional factor is the extent to which electoral systems skew voting results in allocating seats in national legislatures-nearly always in favor of large parties. In the words of Jackman and Miller (1995: 468), "highly disproportional systems require minor parties to 
accumulate many more votes to achieve a given degree of legislative representation, thereby diminishing the benefits of voting for the supporters of those parties. The greater the disproportionality, then, the more likely the votes of minor party supporters are to be wasted. Disproportionality in the translation of votes into legislative seats should therefore lower voter turnout." Electoral disproportionality is measured using an updated version of Lijphart's (1984: 160-165) measure of disproportionality (available in Jackman and Miller, 1995: 485).

Finally, it is frequently argued that cross-national variance in electoral turnout is the product of divergent national procedures for voter registration. In particular, it is hypothesized that electoral turnout will be higher in nations in which the burden of registration is on the state, as opposed to individual citizens. ${ }^{24}$ In measuring the nature of registration systems, we have followed Powell (1986: 38) in distinguishing countries in which registration is either compulsory or automatic from those (in practice, only the U.S. and France) in which registration is the responsibility of potential voters. ${ }^{25}$

Now that several proposed sources of cross-national variance in electoral turnout have been identified, it is possible to construct for Wave III a fuller model of the causes and consequences of cross-regional variation in electoral turnout that incorporates all of the variables introduced above. Before this is done, however, it is necessary to look more closely at the core relationship, that linking turnout and inequality.

Until now, this paper has assumed that the direction of causation leads from electoral turnout to income inequality. This approach is consistent with a good deal of the national-level literature on the topic and, as has been suggested, there is reason to believe that parallel dynamics operate at the regional level. There is, however, also a substantial body of literature suggesting that the direction of causation linking turnout and inequality operates in the opposite direction, from inequality to turnout (see, e.g., Rosenstone and Hansen, 1993). The reasoning is that a high level of inequality in the economic order will contribute to political disaffection and demobilization on the part of low-income groups, leading to low turnout. If income is 
distributed in a relatively egalitarian manner, on the other hand, disaffection will be less pervasive and turnout will be higher. ${ }^{26}$

In reconciling these approaches, it seems plausible to suggest that the relationship between turnout and inequality is mutually reinforcing: low political participation leads to economic inequality, which in turn discourages participation among low-income groups, and so on. In exploring this possibility, it is useful to employ a structural equation method that not only permits both the causes and consequences of cross-regional variance in turnout to be simultaneously modeled but also allows for a nonrecursive relationship between turnout and inequality (see Figure 6). In estimating such a model, the most appropriate technique is three stage least squares, which is closely related to the more familiar two stage least squares structural equation method. (In the words of Kennedy (1998: 166), "this method is the systems counterpart of 2 SLS ... [its estimates] are consistent and in general ... asymptotically more efficient than the 2SLS estimator.") Accordingly, a three stage least squares system of equations was calculated for the relationships depicted in Figure 6. Specifically, in this model the three national-level institutional variables described in the previous section are exogenous with respect to electoral turnout; the left party balance and female-headed household variables are exogenous with respect to income inequality; and inequality and turnout are endogenous with respect to the above variables and to one another, allowing for a feedback relationship between them. To summarize, the following system of simultaneous equations is modeled:

(1) turnout $=\beta_{0}+\beta_{1}(90 / 10$ ratio $)+\beta_{2}$ (registration $)+\beta_{3}$ (electoral disproportionality $)+$ $\beta_{4}$ (nationally competitive elections); and

(2) $90 / 10$ ratio $=\beta_{0}+\beta_{1}$ (turnout) $+\beta_{2}$ (female-headed household) $+\beta_{3}$ (left party balance)

The results are reported in Table 5. As can be seen, the system of structural equations confirms the nonrecursive nature of the relationship between turnout and income inequality: when the direction of causation runs from turnout to inequality, the relationship is negative and statistically significant $(\mathrm{p}<.001)$, and when the direction of causation runs from inequality to 
turnout, the relationship is also negative, although much more weakly. With respect to the other variables, the three-stage least squares system of simultaneous equations demonstrates relationships that are quite similar to those found in the single-equation models reported earlier. For example, in the equation explaining variance in regional inequality, the female-headed household variable continues to be a significant predictor, while the left party balance variable continues not to be. With respect to our variables measuring the institutional sources of crossnational variance in turnout, we find that our registration variable is a strong predictor of electoral turnout in the expected positive direction, that our nationally competitive elections variable is also related to turnout, but more weakly, and that our electoral disproportionality variable is not significantly related in either direction to turnout. ${ }^{27}$

In sum, a three stage least squares model that includes a number of control variables, incorporates several proposed sources of cross-national variance in turnout, and allows for a nonrecursive relationship between inequality and turnout confirms the central conclusion of this paper that electoral turnout is an important factor in explaining cross-regional variance in income inequality. More generally, this analysis illustrates the value of regional-level data in supplementing and extending conclusions based on national-level analysis. The system of structural equations reported above would have been very difficult to estimate for the 15 or so cases for which inequality data are available at the national level, but complex analyses of this sort can readily be conducted for the much larger number of cases for which regional data are available.

\section{CONCLUSION}

The intention of this paper has been to offer an exploratory empirical analysis of the subnational dimension of income inequality. It is hoped that the data reported here will be useful to future researchers who wish to re-examine a variety of relationships that have to this point been examined primarily at the national level. 
More broadly, analysis at the level of subnational regions goes a long way toward addressing a classic research design problem facing the field of comparative politics, the "many variables-few cases" problem (Lijphart, 1971: 685-687). As has been shown, regional analysis increases the number of cases available to those analyzing income inequality in the developed countries more than tenfold. In practice, degrees-of-freedom problems are compounded by the fact that small-n studies are frequently dominated by individual cases, all too often prompting researchers to resort to such vague notions as "American exceptionalism."

Substantively, the above analysis is significant in that it confirms the well-known national-level relationship between electoral turnout and income inequality at another level of aggregation. The fact that regional-level analysis permits much more complex multivariate and multi-equation models than are possible at the national level makes its use even more valuable.

Obviously, regional analysis is not a panacea. For one thing, regions themselves vary considerably in size, and regional figures often represent averages of diverse sub-regionsalthough not nearly as much so as national figures. For another, collecting regional data can be difficult, particularly for non-federal countries, although this is becoming less true with the growing use of the European Union's Nomenclature for Territorial Units (NUTS), which generally coincides with LIS regions. Still, the opportunity afforded by subnational analysis for profitably revisiting old questions and addressing new ones makes it likely that studies at this level will become an ever more prominent part of the literature of cross-national analysis in years to come

\section{BIBLIOGRAPHY}

Atkinson, A.B., L. Rainwater and T. M. Smeeding (1995) Income Distribution in OECD Countries: Evidence from the Luxembourg Income Study. Paris: Organization for Economic Cooperation and Development.

Atkinson, A. B. and A. Brandolini (forthcoming, 2001) Promise and Pitfalls in the Use of "Secondary" Data-Sets: Income Inequality in OECD Countries as a Case Study. Journal of Economic Literature 39. 
Australian Electoral Commission (1998) Electoral Pocketbook. Canberra: Australian Electoral Commission.

Australian Electoral Commission $(1987,1993)$ Election Statistics: National Results. Canberra: Australian Electoral Commission.

Berry, W. D. (1993) Understanding Regression Assumptions. Newbury Park, CA: Sage University Paper on Quantitative Applications in the Social Sciences, 07-092.

Buhmann, B., L. Rainwater, G. Schmaus and T. M. Smeeding (1988) Equivalence Scales, WellBeing, Inequality, and Poverty: Sensitivity Estimates Across Ten Countries Using the Luxembourg Income Study (LIS) Database. Review of Income and Wealth 34: 115-142.

Butler, D. and D. Kavanaugh (1988) The British General Election of 1987. New York: St. Martin's Press.

Butler, D. and D. Kavanaugh (1992) The British General Election of 1992. New York: St. Martin's Press.

Campbell, D. T. (1963) “From Description to Experimentation: Interpreting Trends in QuasiExperiments." In Problems in Measuring Change, edited by C. W. Harris, pp. 212-242. Madison, WI: University of Wisconsin Press.

Caramani, D. (2000) The Societies of Europe: Elections in Western Europe Since 1815: Electoral Results by Constituency. New York: Grove's Dictionaries.

Castles, F. G. and P. Mair (1984) Left-Right Political Scales: Some Expert Judgments. European Journal of Political Research 12: 73-88.

Cline, W. R. (1997) Trade and Income Distribution. Washington, DC: Institute for International Economics.

Cook, R.D. and S. Weisberg (1995) Applied Regression Including Computing and Graphics. New York: John Wiley and Sons.

Crepaz, M. M. L. (1998) Inclusion Versus Exclusion: Political Institutions and Welfare Expansion. Comparative Politics 31: 61-80. 
Cusack, T. R. (1997) Partisan Politics and Public Finance: Changes in Public Spending in the Industrialized Democracies, 1955-1989. Public Choice 91: 375-395.

Dahl, R. A. (1971) Polyarchy: Participation and Opposition. New Haven: Yale University Press.

Deininger, K. and L. Squire (1996) A New Data Set Measuring Income Inequality. World Bank Economic Review 10: 565-91.

Firebaugh, G. (1999) Empirics of World Income Inequality. American Journal of Sociology 104: 1597-1630.

Franklin, M. N. (1996) “Electoral Participation.” In Comparing Democracies: Elections and Voting in Global Perspective, edited by L. LeDuc, R. G. Niemi and P. Norris, pp. 216235. Thousand Oaks, CA: Sage.

Franzese, R., Jr. (forthcoming) Comparative Democratic Mismanagement of the Keynesian Welfare State. New York: Cambridge University Press.

Galbraith, J. K. (1998) Created Unequal: The Crisis in American Pay. New York: Free Press.

Garrett, G. (2001) The Distributive Consequences of Globalization. Unpublished manuscript, Yale University.

Gottschalk, P. and T. M. Smeeding (1997) Cross-National Comparisons of Earnings and Income Inequality. Journal of Economic Literature 35: 633-687.

Gustafsson, B. and M. Johansson (1999) In Search of Smoking Guns: What Makes Income Inequality Vary over Time in Different Countries? American Sociological Review 64: $585-605$

Hicks, A. and D. H. Swank (1992) Politics, Institutions, and Welfare Spending in Industrialized Democracies, 1960-82. American Political Science Review 86: 658-674.

Highton, B. (1997) Easy Registration and Voter Turnout. The Journal of Politics 59: 565-575. International Institute for Democracy and Electoral Assistance (2001) Voter Turnout: A Global Survey. Stockholm, Sweden, www.idea.int/voter_turnout. 
International Monetary Fund [IMF] (1997) Government Finance Statistics Yearbook.

Washington, DC: International Monetary Fund.

Jackman, R. W. (1987) Political Institutions and Voter Turnout in the Industrial Democracies. American Political Science Review 81: 405-424.

Jackman, R. W. and Ross A. Miller (1995) Voter Turnout in the Industrial Democracies During the 1980s. Comparative Political Studies 27: 467-492.

Jesuit, David K. (2001) “The Politics of Income Inequality and Poverty in the Developed World.” Doctoral dissertation, Loyola University Chicago.

Kamerman, S. B. (1995) "Gender Role and Family Structure: Changes in the Advanced Industrial West." In Poverty, Inequality and the Future of Social Policy: Western States in the New World Order, edited by K. McFate, R. Lawson and W. J. Wilson, pp. 231256. New York: Russell Sage Foundation.

Kennedy, P. (1998) A Guide to Econometrics. $4^{\text {th }}$ ed. Malden, MA: Blackwell.

Key, V.O. (1949) Southern Politics in State and Nation. New York: Alfred A. Knopf.

Lijphart, A. (1971) Comparative Politics and the Comparative Method. American Political Science Review 65: 687-693.

Lijphart, A. (1984) Democracies: Patterns of Majoritarian and Consensus Government in Twenty-One Countries. New Haven: Yale University Press.

Lijphart, A. (1997) Unequal Participation: Democracy's Unsolved Dilemma. American Political Science Review 91: 1-14.

Pampel, F. and J. B. Williamson (1989) Age, Class, Politics and the Welfare State. Cambridge: Cambridge University Press.

Powell, G. B., Jr. (1986) American Voter Turnout in Comparative Perspective. American Political Science Review 80: 17-43.

Rosenstone, S. and J. M. Hansen (1993) Mobilization, Participation and Democracy in America. New York: Macmillan. 
Skocpol, T. and E. Amenta (1989) “Taking Exception: Explaining the Distinctiveness of American Public Policies in the Last Century." In The Comparative History of Public Policies, edited by F.G. Castles, pp. 292-333. London: Polity Press.

Statistics Canada (2001) Canadian Statistics: Government: Elections, www.statcan.ca/ English/Pgbd/State/Government.

Tukey, J. W. (1977) Exploratory Data Analysis. Reading, MA: Addison-Wesley.

United States Federal Election Commission (2001) Elections and Voting, www.fec.gov/ elections.html.

Verba, S., N. H. Nie and J. Kim (1978) Participation and Political Equality: A Seven-Nation Comparison. Cambridge: Cambridge University Press.

Wallerstein, M. (1999) Wage-Setting Institutions and Pay Inequality in Advanced Industrial Societies. American Journal of Political Science 43: 649-680.

Wolfinger, R. E., D. P. Glass and P. Squire (1990) Predictors of Electoral Turnout: An International Comparison. Policy Studies Review 9: 551-774.

World Bank (1992, 1997) World Development Report. New York: Oxford University Press. 


\section{ENDNOTES}

${ }^{1}$ The LIS calls this process "lisification," and it offers extensive documentation of the methodology whereby national surveys have been reworked to conform to a common set of definitions. To preserve the confidentiality of household-level income data and to prevent their use for commercial purposes, the raw data assembled by the LIS can be accessed only at some level of aggregation, and are restricted to users who have signed a pledge that they will be used solely for purposes of academic research. As a practical matter, data are accessed by submitting SPSS, SAS or STATA commands to the LIS computers in Luxembourg via E-mail and receiving corresponding output in return. For more information on the LIS see Atkinson et al. (1995) and the LIS website www.lis.ceps.lu.

${ }^{2}$ As has been indicated, this analysis focuses on the developed world. Excellent discussions of global inequality are offered by Firebaugh (1999) and Garrett (2001).

${ }^{3}$ One of the advantages of the LIS is that it permits a wide range of options with respect to equivalence scales. The method described above produces what the LIS calls "person weights," in which the basic unit is an individual household member. (Many of the national surveys that are the source of LIS data also employ sample weights, which adjust the weight accorded each household in a sample on the basis of known characteristics of the underlying population.) While the methods employed here are commonly used in analyzing LIS data, there are many other possible choices of equivalence scales, each with a distinct effect on the resulting statistics. For a detailed discussion see Buhmann et al. (1988).

${ }^{4}$ LIS data sets sometimes include two geographical variables representing different levels of aggregation. When two breakdowns are available, the more detailed is generally employed. Several LIS surveys do not include geographical information. These countries are not included in the analysis.

${ }^{5}$ The only exception on this score is Belgium, for which a more detailed regional breakdown than the three-part Belgian federation is employed. 
${ }^{6}$ Each of these indicators has advantages and disadvantages in summarizing LIS household-level data. An advantage of percentile ratios is that they are relatively immune to problems arising from incompatibilities in national surveys with respect to "top coding" and "bottom coding" of income. Top coding occurs when surveys protect the confidentiality of the highest income recipients by coding their income at some arbitrary maximum value, while bottom coding reflects differences in national procedures for coding income that is very low or negative. Since top coded or bottom coded values do not ordinarily extend as high as the 90th or as low as the 10th percentile, percentile ratios are unaffected by inconsistencies in this area. Gini indexes, which take into account all income groups, offer a broader measure of income inequality than percentile ratios. They are, however, sensitive to top and bottom coding problems - although not as much so as such widely used indexes as the Atkinson or the Theil (Atkinson et al., 1995: 31). The Gini indexes in this paper have employed the top and bottom coding procedures described in Gottschalk and Smeeding (1997: 661).

${ }^{7}$ Although income inequality is generally conceived in relative terms, it is true that a household with relatively low income in a rich country might be objectively better off than a household with relatively higher income in a poor country. Since LIS data are expressed in current national currencies for different years, it is difficult to express incomes in a common metric across surveys with any degree of precision, especially adjusting for purchasing prices. (The critical importance of this adjustment is demonstrated by Firebaugh (1999)). A sense of the income level in the countries covered in this study can be achieved by comparing Purchasing Price Parity-adjusted per capita income figures for LIS countries for 1990 and 1995, the approximate years of LIS Wave III and Wave IV surveys. These are offered in Table 2.

${ }^{8}$ The dates of LIS surveys are listed in Figures 1-4. "Wave III" figures actually include data for two Wave II countries, Belgium and Italy. The reason is that the Wave III Belgian and Italian surveys employ only crude three-part regional breakdowns whereas Wave II (mid-1980s) surveys employ detailed breakdowns more similar to those of other countries. A regional 
breakdown is also available for Luxembourg, but it is not included because its regions are so much smaller than those for any other country.

${ }^{9}$ These figures were computed in close coordination with David Jesuit, Project Manager and Senior Research Associate of the Luxembourg Income Study. I am, however, fully responsible for any errors. Details on the precise methods employed are available in the "Key figures" part of the LIS website, www.lis.ceps.lu. LIS surveys are occasionally revised or corrected, and I plan to update these figures accordingly and provide them to interested researchers.

${ }^{10} \mathrm{~A}$ standard box plot also identifies by name any individual cases that fall more than 1.5 box lengths from the upper or lower edge of a box. Because the data reported here represent ratios of various sorts, they are not highly skewed. Still, there are, for many countries, several regions that fall outside the whiskers on their box plots. These are not reported because to do so would be misleading: A region that falls outside Finland's whiskers, which reflect very little intra- or inter-regional variation, would fall well within the boxes many other countries.

${ }^{11}$ There is a great deal more variance within than across regions. Analyses of variance partitioning total variance into within- and between-region components have been conducted for each LIS Wave III survey. In every case at least $90 \%$ of the total variance in adjusted household income is intra-regional.

${ }^{12}$ The District of Columbia is included as a region, so there are 51 U.S. regions. At times, these regions will, for convenience, be referred to as "states."

${ }^{13}$ In making over-time comparisons, the former German Democratic Republic Länder, for which Wave III data are unavailable, are excluded. In addition, it was necessary to combine two pairs of Wave IV Italian regions, Basilicata/Campania, and Abruzzi/Molise, to make them consistent with Wave III data.

${ }^{14}$ This line of reasoning has recently been formally modeled and empirically tested by Franzese (forthcoming: chapter 2) who re-examines the familiar "median voter" hypothesis 
positing that the difference between the income of the median voter and the median income earner is negatively associated with the extent of public redistributive efforts.

${ }^{15}$ In an extensive survey of national sources, Atkinson et al. (1995: 61-80) could find fewer than half a dozen national time series, and even these varied considerably in their length, income coverage and equivalence scales. In an effort to conduct longitudinal analyses of income inequality at the national level, some researchers have employed OECD's STAN database, which provides annual data on inter-sectoral earnings inequality (see, e.g., Galbraith, 1998). These data are, however, less desirable for many purposes than LIS data because they do not cover nonworkers, exclude income from the public sector and represent inter-industry rather than interhousehold distributions. Similarly, Deininger and Squire (1996) have compiled figures on income inequality that have been widely distributed as part of the World Income Inequality Database maintained by the United Nations University. These figures are, however, far less comparable across the developed countries than LIS figures in that they are inconsistent with respect to equivalence scales and in their treatment of taxes and transfers (Atkinson and Brandolini, forthcoming, 2001).

${ }^{16}$ Switzerland is another deviant case with respect to electoral turnout, but it is not examined here because it is not included in LIS Waves III or IV.

${ }^{17}$ National-level turnout figures are from International Institute for Democracy and Electoral Assistance (2001); turnout is expressed relative to the voting aged population. Regional-level turnout is measured as the proportion of persons "entitled to vote" who voted in the election to the lower house of a country's legislature in the same year as or immediately prior to a LIS survey, with the exception of the U.S., in which turnout is measured as the proportion of the voting aged population that voted for president in the most recent presidential election (which, of course, coincides with an election to the House of Representatives). Where separate data are available for invalid votes, they are included in vote totals, on the assumption that these represent persons who intended to vote even if their vote was not registered. Data for Belgium, 
Denmark, Finland, France, Germany, Italy and Spain are from Caramani (2000), which provides extensive historical data for European countries in computer-readable form. In some cases, raw regional data from this source were adjusted to make them compatible with LIS boundaries, and a few minor gaps were filled with reference to national sources. Data for Australia are from Australian Electoral Commission (1998, 1993, 1987); for Canada from Statistics Canada (2001); for the U.K. from Butler and Kavanaugh $(1988,1992)$; and for the U.S. from the Federal Election Commission (2001). Election years are: Australia, 1987, 1993; Belgium, 1987; Canada, 1988, 1993; Denmark, 1988; Finland, 1987, 1995; France, 1988, 1993; Germany, 1987, 1994; Italy, 1983, 1994; Spain, 1989; U.K., 1987, 1995; and U.S., 1988, 1992.

${ }^{18}$ This analysis includes four countries for which LIS income data are available but are not broken down by region: Austria, Ireland, Norway and the Netherlands. $B$ represents the unstandardized regression coefficient, beta weight is the standardized regression coefficient, $t$ is the $t$ ratio, and $p$ is the two-tailed significance level.

${ }^{19}$ This reflects spatial autocorrelation rather than the more common temporal autocorrelation. In the words of William Berry (1993: 71-72), "although autocorrelation is typically not as great a concern in cross-sectional models as in time-series designs, spatial autocorrelation is possible in some situations. . . . [A] substantive context in which analysts need to be concerned with the possibility of spatial autocorrelation is when the units observed are political jurisdictions..." An alternative way of accounting for country effects is to construct GLS regressions that estimate and adjust for spatial autocorrelation. This has been done, with results that are similar to, but generally stronger than, those reported here.

${ }^{20}$ Finland, France and Italy are excluded to facilitate comparison with the multivariate analyses that will follow, in which these cases are excluded.

${ }^{21}$ Left party balance is measured as of the election for which turnout is reported. I am grateful to David K. Jesuit for providing these data, which are documented in Jesuit (2001).

${ }^{22}$ Left party balance values are missing for Finland, France and Italy, so they are not 
included in the analysis for Wave IV. In order to make the bivariate and multivariate analyses comparable, these countries were (as was noted) also excluded from the bivariate analysis.

${ }^{23}$ These regressions employ OLS and do not, of course, include dummies.

${ }^{24}$ The U.S. is unusual in that there is some variance across the U.S. states in the restrictiveness of registration procedures. Although the onus of registration is in all cases on individual citizens, several states permit voters to register on the same day they vote rather than, as is typical, a month or more earlier. Wolfinger et al. (1990; see also Highton, 1997) found turnout in these states to be somewhat higher than in states with more restrictive laws.

${ }^{25}$ Some scholars have also considered the fact that voting is compulsory in a few OECD countries. In practice, however, laws mandating voting impose small penalties and are rarely enforced. An interesting case is that of Italy, whose law mandating voting was rescinded after the 1992 election. Turnout in the elections before and after this change was almost identical.

${ }^{26}$ With only two time points that are only a few years apart, it is difficult to offer a diachronic analysis of causal priority. One straightforward way of assessing causal direction under such circumstances is to construct cross-lagged correlations comparing the relationship between the purported independent variable at time $t-1$ and the purported dependent variable at time $t$ with the relationship between the purported dependent variable at time $t-1$ and the purported independent variable at time $t$ (Campbell, 1963: 235-242), with the expectation that the former will be higher than the latter. The above-mentioned correlations have been constructed for turnout and the 90/10 ratio of adjusted household income inequality for LIS Waves III and IV. The first correlation is indeed higher than the second.

${ }^{27}$ The three stage least squares model estimated above is quite complex and includes several national-level variables, so country dummies are not included. On an experimental basis, country dummies were included in equation (1) as additional exogenous variables. The results did not differ greatly from those reported here; specifically, the relationship between turnout and inequality continued to be negative and significant. 
Table 1 Income Inequality, LIS Waves III and IV

\begin{tabular}{|c|c|c|c|c|c|c|c|}
\hline & & \multicolumn{3}{|c|}{ Wave III } & \multicolumn{3}{|c|}{ Wave IV } \\
\hline & & \multirow[b]{2}{*}{$90 / 10$} & \multicolumn{2}{|c|}{ REG/ } & \multirow[b]{2}{*}{$90 / 10$} & \multirow{3}{*}{$\begin{array}{c}\text { GINI } \\
.283\end{array}$} & \multirow{2}{*}{$\begin{array}{l}\text { REG/ } \\
\text { NAT }\end{array}$} \\
\hline & & & GINI & NAT & & & \\
\hline \multirow[t]{7}{*}{ Australia } & $\overline{\mathrm{ACT}}$ and NT & 4.33 & .284 & 1.17 & 3.97 & & 1.21 \\
\hline & New South Wales & 4.31 & .307 & 1.02 & 4.66 & .318 & 1.03 \\
\hline & Queensland & 4.09 & .310 & .91 & 4.25 & .310 & .97 \\
\hline & S. Australia & 4.14 & .307 & .92 & 3.96 & .293 & .99 \\
\hline & Tasmania & 3.97 & .297 & .93 & 3.62 & .290 & .93 \\
\hline & Victoria & 4.02 & .292 & 1.05 & 4.44 & .314 & .97 \\
\hline & W. Australia & 4.14 & .300 & 1.01 & 4.14 & .294 & 1.00 \\
\hline \multirow[t]{9}{*}{$\overline{\text { Belgium }}$} & Antwerp & 2.67 & .223 & 1.03 & - & - & - \\
\hline & Brabant & 2.85 & .231 & 1.04 & - & - & - \\
\hline & E. Flanders & 2.69 & .213 & 1.05 & - & - & - \\
\hline & Hainaut & 2.65 & .226 & .88 & - & - & - \\
\hline & Liege & 2.71 & .226 & 1.01 & - & - & - \\
\hline & Limburg & 2.36 & .189 & .87 & - & - & - \\
\hline & Luxembourg & 3.00 & .227 & .98 & - & - & - \\
\hline & Namur & 2.71 & .223 & 1.00 & - & - & - \\
\hline & W. Flanders & 2.71 & .237 & .98 & - & - & - \\
\hline \multirow[t]{10}{*}{$\overline{\text { Canada }}$} & Alberta & 3.94 & .282 & 1.06 & 3.99 & .285 & 1.02 \\
\hline & British Columbia & 3.91 & .275 & 1.05 & 3.94 & .279 & 1.07 \\
\hline & Manitoba & 3.72 & .277 & .88 & 3.71 & .267 & .94 \\
\hline & New Brunswick & 3.49 & .265 & .90 & 3.91 & .277 & .86 \\
\hline & Newfoundland & 3.71 & .265 & .81 & 3.97 & .279 & .81 \\
\hline & Nova Scotia & 3.54 & .264 & .88 & 3.88 & .281 & .88 \\
\hline & Ontario & 3.72 & .272 & 1.10 & 3.76 & .275 & 1.10 \\
\hline & Prince Edward I. & 3.26 & .261 & .85 & 3.02 & .253 & .88 \\
\hline & Quebec & 3.61 & .270 & .91 & 3.72 & .267 & .91 \\
\hline & Saskatchewan & 3.84 & .284 & .88 & 3.87 & .282 & .87 \\
\hline \multirow[t]{16}{*}{$\overline{\text { Denmark }}$} & Aarhus & 3.02 & .238 & 1.01 & - & - & - \\
\hline & Bornholm & 2.97 & .163 & 1.04 & - & - & - \\
\hline & Copenhagen County & 3.26 & .253 & 1.09 & - & - & - \\
\hline & Copenhagen Metro & 3.41 & .247 & .84 & - & - & - \\
\hline & Frederiksberg & 3.75 & .276 & .96 & - & - & - \\
\hline & Frederiksberg County & 3.47 & .234 & 1.18 & - & - & - \\
\hline & Fyn & 3.08 & .231 & .97 & - & - & - \\
\hline & Nordjylland & 3.18 & .230 & .96 & - & - & - \\
\hline & Ribe & 3.04 & .208 & 1.04 & - & - & - \\
\hline & Ringkobing & 2.69 & .212 & 1.01 & - & - & - \\
\hline & Roskilde & 3.15 & .228 & 1.13 & - & - & - \\
\hline & Sonderjylland & 3.05 & .221 & .96 & - & - & - \\
\hline & Storstrom & 3.00 & .221 & .96 & - & - & - \\
\hline & Vejle & 2.89 & .223 & 1.01 & - & - & - \\
\hline & Vestjaelland & 3.21 & .232 & 1.00 & - & - & - \\
\hline & Viborg & 2.77 & .207 & .98 & - & - & - \\
\hline \multirow[t]{7}{*}{ Finland } & Central Finland & 2.64 & .207 & .94 & 2.69 & .227 & .96 \\
\hline & Home Province & 2.55 & .208 & .98 & 2.64 & .225 & 1.01 \\
\hline & Kuopio & 2.51 & .207 & .92 & 2.76 & .234 & .94 \\
\hline & Kymi & 2.39 & .189 & 1.00 & 2.90 & .237 & 1.02 \\
\hline & Lapland & 2.42 & .198 & .97 & 2.65 & .210 & .96 \\
\hline & Mikkeli & 2.75 & .221 & .94 & 2.58 & .226 & .96 \\
\hline & North Karelia & 2.58 & .201 & .92 & 2.55 & .207 & .93 \\
\hline
\end{tabular}


Table 1 Income Inequality, LIS Waves III and IV continued

\begin{tabular}{|c|c|c|c|c|c|c|c|}
\hline & & \multicolumn{3}{|c|}{ Wave III } & \multicolumn{3}{|c|}{ Wave IV } \\
\hline & & \multirow[b]{2}{*}{$90 / 10$} & \multicolumn{2}{|c|}{ REG/ } & \multirow[b]{2}{*}{$90 / 10$} & \multicolumn{2}{|r|}{ REG/ } \\
\hline & & & GINI & NAT & & GINI & NAT \\
\hline \multirow[t]{5}{*}{ Finland } & Oland Islands & 2.68 & .210 & 1.00 & 2.89 & .227 & .97 \\
\hline & Oulu & 2.35 & .189 & .97 & 2.57 & .200 & .96 \\
\hline & Turku/Pori & 2.62 & .209 & .97 & 2.59 & .214 & 1.000 \\
\hline & Uusimaa & 2.79 & .208 & 1.14 & 2.79 & .233 & 1.07 \\
\hline & Vaasa & 2.62 & .204 & .95 & 2.51 & .216 & .95 \\
\hline \multirow[t]{22}{*}{ France } & Alsace & 2.98 & .247 & 1.09 & 3.41 & .273 & 1.18 \\
\hline & Aquitaine & 3.63 & .280 & .94 & 3.67 & .278 & .97 \\
\hline & Auvergne & 3.64 & .260 & .92 & 3.25 & .252 & .95 \\
\hline & Basse-Normandie & 2.97 & .240 & .94 & 3.19 & .266 & .91 \\
\hline & Bourgogne & 3.11 & .244 & .97 & 3.29 & .269 & .95 \\
\hline & Brittany & 3.58 & .282 & .99 & 3.10 & .270 & .92 \\
\hline & Centre & 3.24 & .262 & 1.04 & 3.08 & .253 & .99 \\
\hline & Champaigne-Ardennes & 3.10 & .250 & .99 & 3.19 & .257 & .93 \\
\hline & Corsica & 5.47 & .337 & 1.05 & 3.60 & .261 & .78 \\
\hline & Franche-Comte & 2.76 & .267 & .85 & 3.48 & .250 & .98 \\
\hline & Haute-Normandie & 3.19 & .265 & .92 & 2.74 & .232 & 1.04 \\
\hline & Ile-de-France & 3.57 & .280 & 1.27 & 3.97 & .312 & 1.26 \\
\hline & Langeudoc-Roussillon & 4.39 & .337 & .81 & 3.42 & .269 & .93 \\
\hline & Limousin & 3.24 & .277 & 1.04 & 4.19 & .339 & .87 \\
\hline & Lorraine & 2.73 & .250 & .93 & 2.85 & .254 & .96 \\
\hline & Midi-Pyrenees & 3.54 & .270 & .96 & 3.31 & .270 & .93 \\
\hline & Nord-Pas-de-Calais & 3.22 & .267 & .84 & 3.44 & .263 & .87 \\
\hline & Pays de la Loire & 3.41 & .265 & .99 & 3.30 & .262 & .96 \\
\hline & Picardie & 3.61 & .261 & .95 & 3.43 & .279 & .94 \\
\hline & Poitou-Charentes & 3.55 & .285 & .86 & 3.72 & .268 & .95 \\
\hline & Provence-Alpes-Cote & 3.36 & .291 & 1.02 & 3.78 & .303 & .97 \\
\hline & Rhone-Alpes & 3.51 & .296 & 1.03 & 3.37 & .271 & 1.00 \\
\hline \multirow[t]{16}{*}{$\overline{\text { Germany }}$} & Baden-Wurttemberg & 3.14 & .269 & 1.02 & 3.16 & .248 & 1.06 \\
\hline & Bavaria & 3.00 & .260 & 1.05 & 3.15 & .262 & 1.07 \\
\hline & Brandenburg-W.Pom. & - & - & - & 2.47 & .201 & .87 \\
\hline & Bremen & 2.86 & .201 & 1.00 & 3.10 & .248 & .77 \\
\hline & E. Berlin & - & - & - & 2.73 & .227 & 1.08 \\
\hline & Hamburg & 2.29 & .197 & .97 & 2.65 & .212 & 1.13 \\
\hline & Hesse & 2.78 & .229 & 1.07 & 3.45 & .298 & 1.10 \\
\hline & Lower Saxony & 2.99 & .253 & .96 & 3.39 & .261 & 1.01 \\
\hline & Mecklenburg & - & - & - & 2.67 & .203 & .87 \\
\hline & N. Rhine-Westphalia & 2.93 & .236 & .97 & 3.11 & .273 & 1.01 \\
\hline & Rhineland-Palatinate & 2.69 & .239 & .99 & 4.55 & .266 & .98 \\
\hline & Saxony & - & - & - & 2.31 & .193 & .83 \\
\hline & Saxony-Anhalt & - & - & - & 2.41 & .214 & .90 \\
\hline & Schleswig Holstein & 2.62 & .239 & .90 & 4.20 & .284 & 1.04 \\
\hline & Thuringia & - & - & - & 2.61 & .193 & .87 \\
\hline & W. Berlin & 2.71 & .195 & 1.05 & 3.55 & .249 & 1.13 \\
\hline \multirow[t]{5}{*}{ Italy } & Abruzzi* & 3.76 & .332 & .78 & 3.72 & .309 & .94 \\
\hline & Basilicata** & 3.84 & .264 & .80 & 3.70 & .315 & .71 \\
\hline & Calabria** & - & - & - & 5.79 & .382 & .58 \\
\hline & Campania & 4.00 & .295 & .73 & 5.50 & .334 & .75 \\
\hline & Emilia-Romagna & 3.52 & .300 & 1.21 & 3.56 & .296 & 1.31 \\
\hline
\end{tabular}


Table 1 Income Inequality, LIS Waves III and IV continued

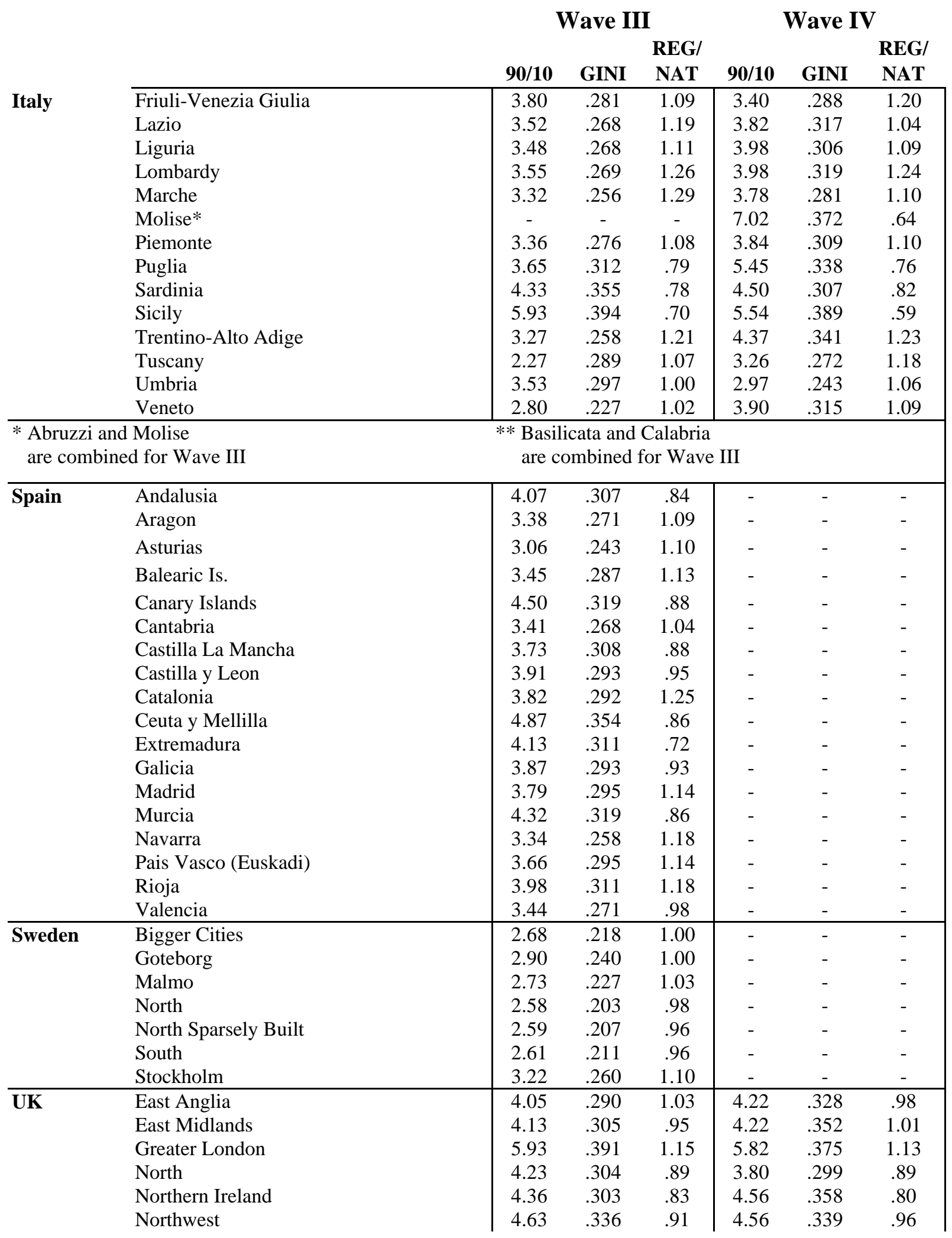


Table 1 Income Inequality, LIS Waves III and IV continued

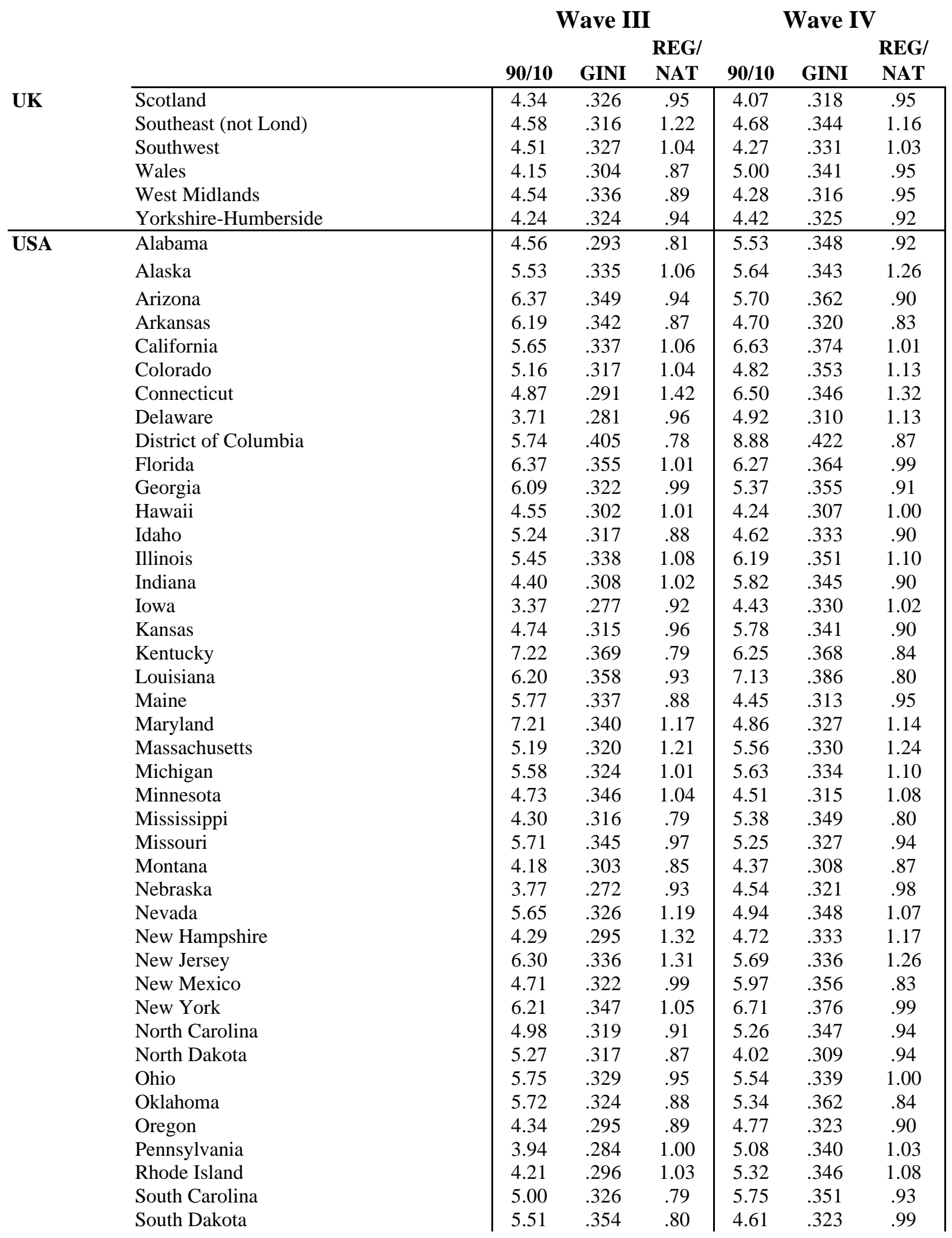


Table 1 Income Inequality, LIS Waves III and IV continued

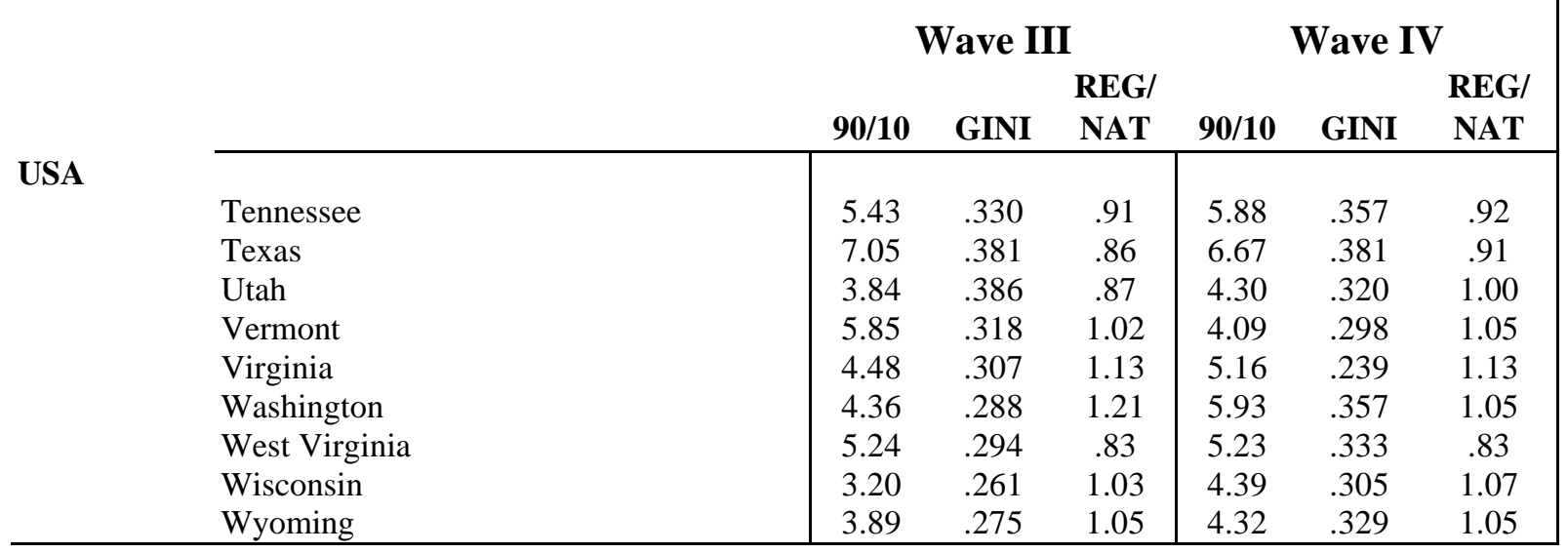

Table 2: Per Capita Income in LIS Countries, 1990 and 1995 19901995

Nominal PPP Adjusted Nominal PPP Adjusted

\begin{tabular}{lllll|}
\hline Australia & 17,000 & 16,050 & 18,720 & 18,940 \\
Belgium & 15,540 & 12,950 & 24,710 & 21,660 \\
Canada & 20,470 & 19,650 & 19,380 & 21,130 \\
Denmark & 22,080 & 15,380 & 29,890 & 21,230 \\
Finland & 26,040 & 15,620 & 20,580 & 17,760 \\
France & 19,490 & 15,200 & 24,990 & 21,030 \\
Germany & 22,320 & 16,290 & 27,510 & 20,070 \\
Italy & 16,830 & 14,550 & 19,020 & 19,870 \\
Spain & 11,020 & 10,840 & 13,580 & 14,520 \\
Sweden & 23,660 & 16,000 & 23,750 & 18,540 \\
U.K. & 16,100 & 14,960 & 18,700 & 19,260 \\
U.S.A. & 21,790 & 21,360 & 26,980 & 26,980
\end{tabular}

Note: Nominal figures represent GNP converted at official exchange rates. Purchasing Price Parity (PPP) reflect GDP and have been adjusted to better reflect comparative living standards. Source: World Bank $(1992,1997)$. 
Table 3 Regressions for Wave III \& IV: All Regions

\begin{tabular}{|c|c|c|c|c|c|c|c|}
\hline & Dependent Variables & Independent Variables & B & $\mathbf{t}$ & sig. & R-Square & $\mathbf{n}$ \\
\hline Wave III & $90 / 10$ & Turnout & -0.04 & -4.99 & $<.001$ & 0.72 & 184 \\
\hline \multirow{2}{*}{ Bivariate } & Gini & Turnout & -0.01 & -3.23 & 0.001 & 0.72 & 184 \\
\hline & Regional/National & Turnout & 0.00 & 1.67 & 0.097 & 0.04 & 184 \\
\hline \multirow{3}{*}{$\begin{array}{l}\text { Wave IV } \\
\text { Bivariate }\end{array}$} & $90 / 10$ & Turnout & -0.04 & -3.21 & 0.002 & 0.63 & 96 \\
\hline & Gini & Turnout & -0.00 & -1.65 & 0.103 & 0.74 & 96 \\
\hline & Regional/National & Turnout & 0.00 & 2.49 & 0.015 & 0.09 & 96 \\
\hline \multirow{9}{*}{$\begin{array}{l}\text { Wave III } \\
\text { Multivariate }\end{array}$} & $90 / 10$ & Turnout & -0.04 & -4.60 & $<.001$ & 0.85 & 184 \\
\hline & & Left Party Balance & 0.01 & 0.88 & 0.382 & & \\
\hline & & Female-Headed Household & 0.02 & 1.50 & 0.135 & & \\
\hline & $\overline{\text { Gini }}$ & Turnout & -0.01 & -2.79 & 0.006 & 0.73 & 184 \\
\hline & & Left Party Balance & -0.00 & -0.28 & 0.835 & & \\
\hline & & Female-Headed Household & 0.00 & 2.23 & 0.027 & & \\
\hline & $\overline{\text { Regional/National }}$ & Turnout & 0.00 & 1.48 & 0.142 & 0.09 & 184 \\
\hline & & Left Party Balance & -0.01 & -2.96 & 0.004 & & \\
\hline & & Female-Headed Household & 0.00 & 0.14 & 0.891 & & \\
\hline \multirow{9}{*}{$\begin{array}{l}\text { Wave IV } \\
\text { Multivariate }\end{array}$} & $90 / 10$ & Turnout & -0.03 & -2.82 & 0.006 & 0.68 & 96 \\
\hline & & Left Party Balance & -0.02 & -0.66 & 0.514 & & \\
\hline & & Female-Headed Household & 0.07 & 3.57 & .001 & & \\
\hline & Gini & Turnout & -0.00 & -1.42 & 0.158 & 0.72 & 96 \\
\hline & & Left Party Balance & -0.01 & -0.62 & 0.536 & & \\
\hline & & Female-Headed Household & 0.00 & 1.79 & 0.077 & & \\
\hline & $\overline{\text { Regional/National }}$ & Turnout & 0.00 & 2.28 & 0.025 & 0.11 & 96 \\
\hline & & Left Party Balance & -0.00 & -1.10 & 0.274 & & \\
\hline & & Female-Headed Household & 0.00 & 0.34 & 0.737 & & \\
\hline
\end{tabular}

Note: The regressions reported above include D-1 dummy variables specifying national-level effects 
Table 4 Regressions for Wave III \& IV: US Only

\begin{tabular}{|c|c|c|c|c|c|c|c|}
\hline & Dependent Variables & Independent Variables & b & $\mathbf{t}$ & sig. & R-square & $\mathbf{n}$ \\
\hline Wave III & $90 / 10$ & Turnout & -0.06 & -2.79 & 0.007 & 0.14 & 51 \\
\hline \multirow[t]{2}{*}{ Bivariate } & Gini & Turnout & -0.01 & -1.77 & 0.082 & 0.06 & 51 \\
\hline & Regional/National & Turnout & 0.01 & 1.00 & 0.322 & 0.02 & 51 \\
\hline Wave IV & $90 / 10$ & Turnout & -0.06 & -3.52 & 0.001 & 0.20 & 51 \\
\hline \multirow[t]{2}{*}{ Bivariate } & Gini & Turnout & -0.00 & -4.11 & 0.000 & 0.26 & 51 \\
\hline & Regional/National & Turnout & 0.00 & 1.71 & 0.093 & 0.06 & 51 \\
\hline \multirow{9}{*}{$\begin{array}{l}\text { Wave III } \\
\text { Multivariate }\end{array}$} & $90 / 10$ & Turnout & -0.04 & -2.03 & 0.048 & 0.19 & 51 \\
\hline & & Left Party Balance & 0.02 & 1.10 & 0.277 & & \\
\hline & & Female-Headed Household & 0.03 & 0.82 & 0.421 & & \\
\hline & $\overline{\text { Gini }}$ & Turnout & -0.00 & -1.09 & 0.280 & 0.17 & 51 \\
\hline & & Left Party Balance & -0.00 & -0.43 & 0.670 & & \\
\hline & & Female-Headed Household & 0.00 & 2.47 & 0.017 & & \\
\hline & Regional/National & Turnout & 0.00 & 0.64 & 0.528 & 0.04 & 51 \\
\hline & & Left Party Balance & -0.00 & -0.90 & 0.371 & & \\
\hline & & Female-Headed Household & 0.00 & 0.01 & 0.992 & & \\
\hline \multirow{9}{*}{$\begin{array}{l}\text { Wave IV } \\
\text { Multivariate }\end{array}$} & $90 / 10$ & Turnout & -0.04 & -3.08 & 0.003 & 0.52 & 51 \\
\hline & & Left Party Balance & -0.01 & -1.97 & 0.055 & & \\
\hline & & Female-Headed Household & 0.16 & 5.38 & $<.001$ & & \\
\hline & $\overline{\text { Gini }}$ & Turnout & -0.00 & -2.63 & 0.011 & 0.30 & 51 \\
\hline & & Left Party Balance & -0.00 & -1.86 & 0.069 & & \\
\hline & & Female-Headed Household & 0.00 & 3.00 & 0.004 & & \\
\hline & Regional/National & Turnout & 0.00 & 1.36 & 0.182 & 0.08 & 51 \\
\hline & & Left Party Balance & -0.00 & -1.18 & 0.243 & & \\
\hline & & Female-Headed Household & 0.00 & 0.44 & 0.664 & & \\
\hline
\end{tabular}

Table 5 Three Stage Least Squares Regression

$\begin{array}{llllllll}\text { Dependent Variables } & \text { Independent Variables } & \text { b } & \text { t } & \text { sig. } & \text { Chi Square } & \text { n }\end{array}$

\begin{tabular}{l|lrrrrr|}
\hline Turnout & $90 / 10$ & -1.27 & -0.27 & 0.786 & 465.53 & 184 \\
& Registration & 18.37 & 4.55 & $<.001$ & & \\
& Nationally Competitive & 3.80 & 1.69 & 0.092 & & \\
& Electoral Disprop. & -0.24 & -1.18 & 0.237 & & \\
& & & & & & \\
& & & & & & \\
\hline $90 / 10$ & Turnout & -0.05 & -9.70 & $<.001$ & 185.75 & 184 \\
& Female-Headed Household & 0.03 & 3.37 & 0.001 & & \\
& Left Party Balance & -0.00 & -1.51 & 0.131 & & \\
\hline
\end{tabular}

Note: Three stage least squares regressions were run with the Stata statistical program. 
Figure 1: 90/10 Ratios, Wave III

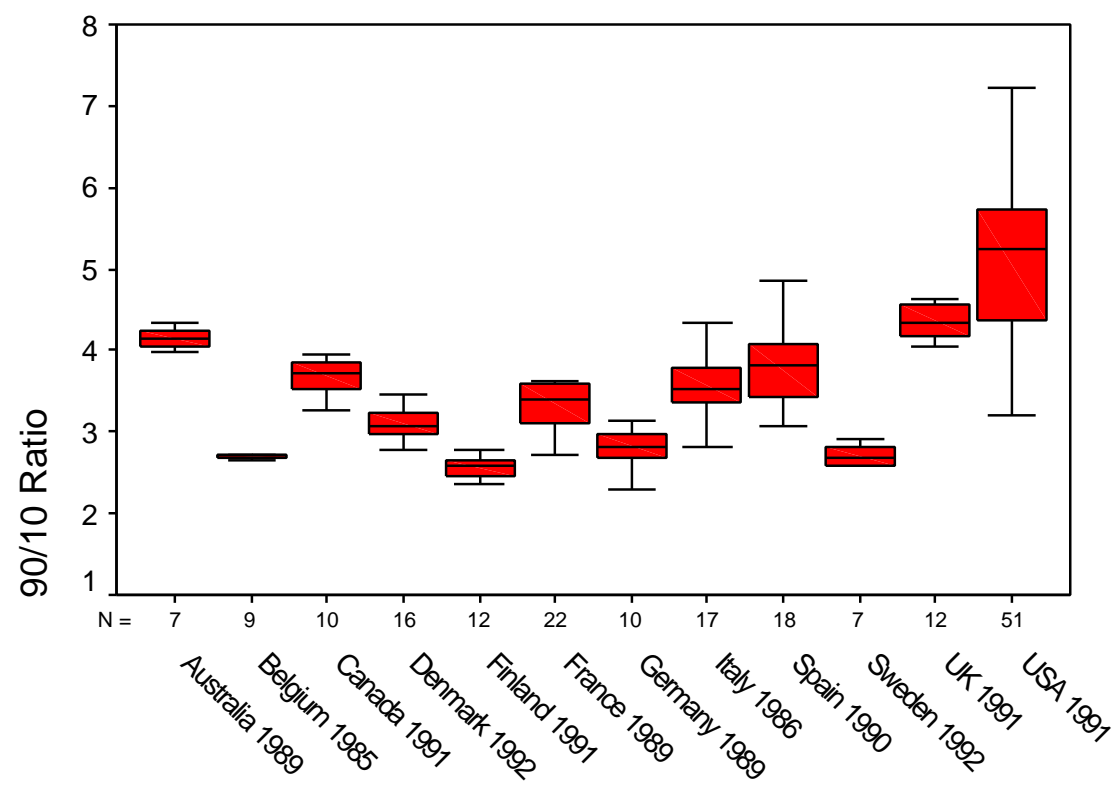

LIS Survey

Figure 2: 90/10 Ratios, Wave IV

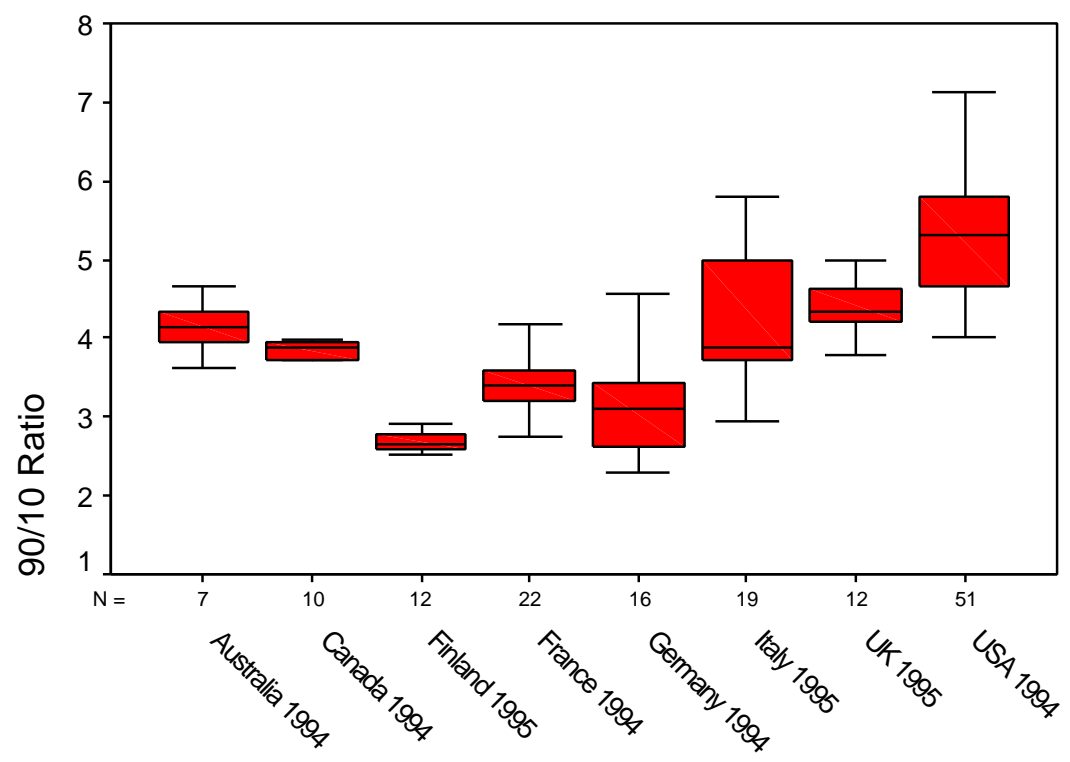

LIS Survey 
Figure 3: Regional/National, Wave III

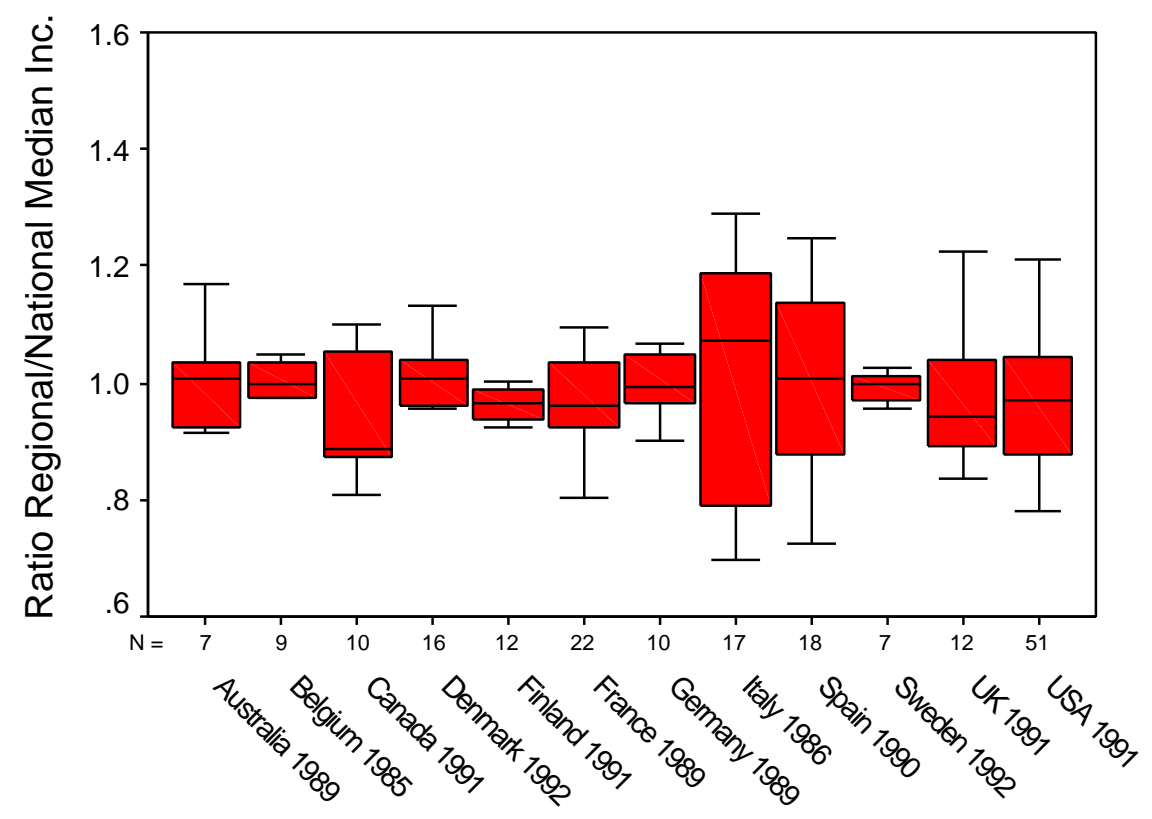

LIS Survey

Figure 4: Regional/National, Wave IV

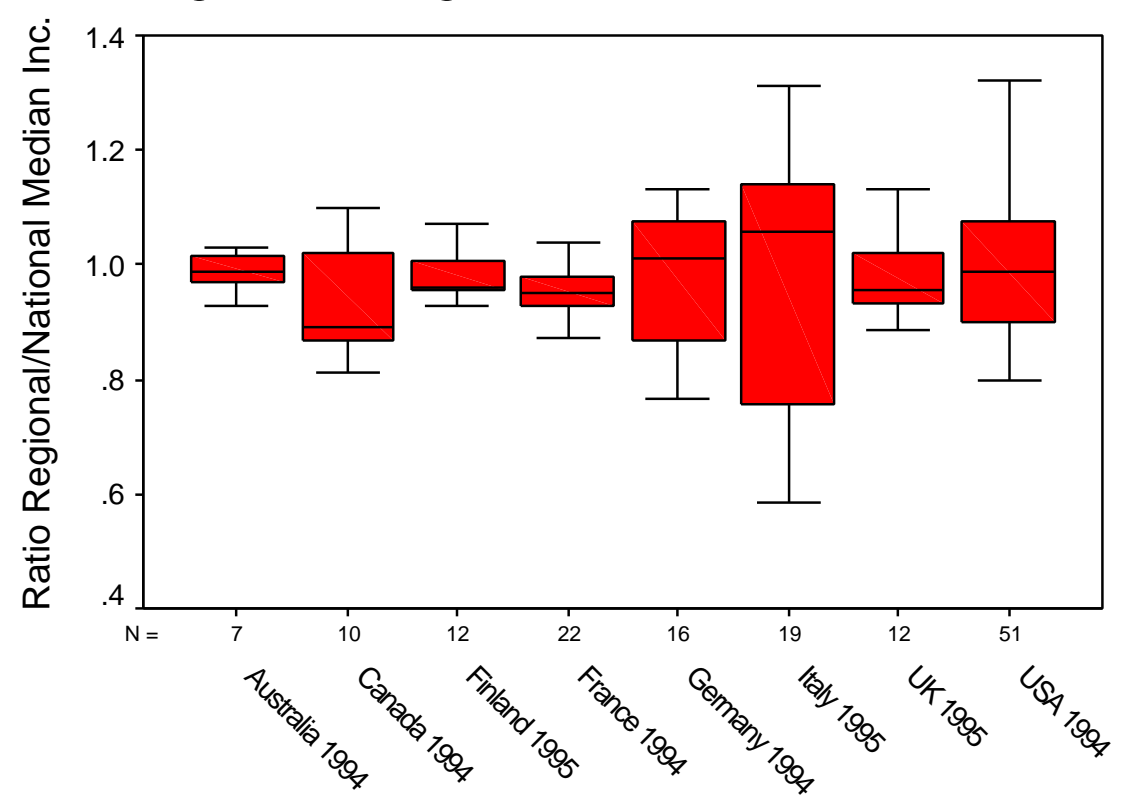

LIS Survey 
Figure 5: Wave III Income Inequality by Turnout

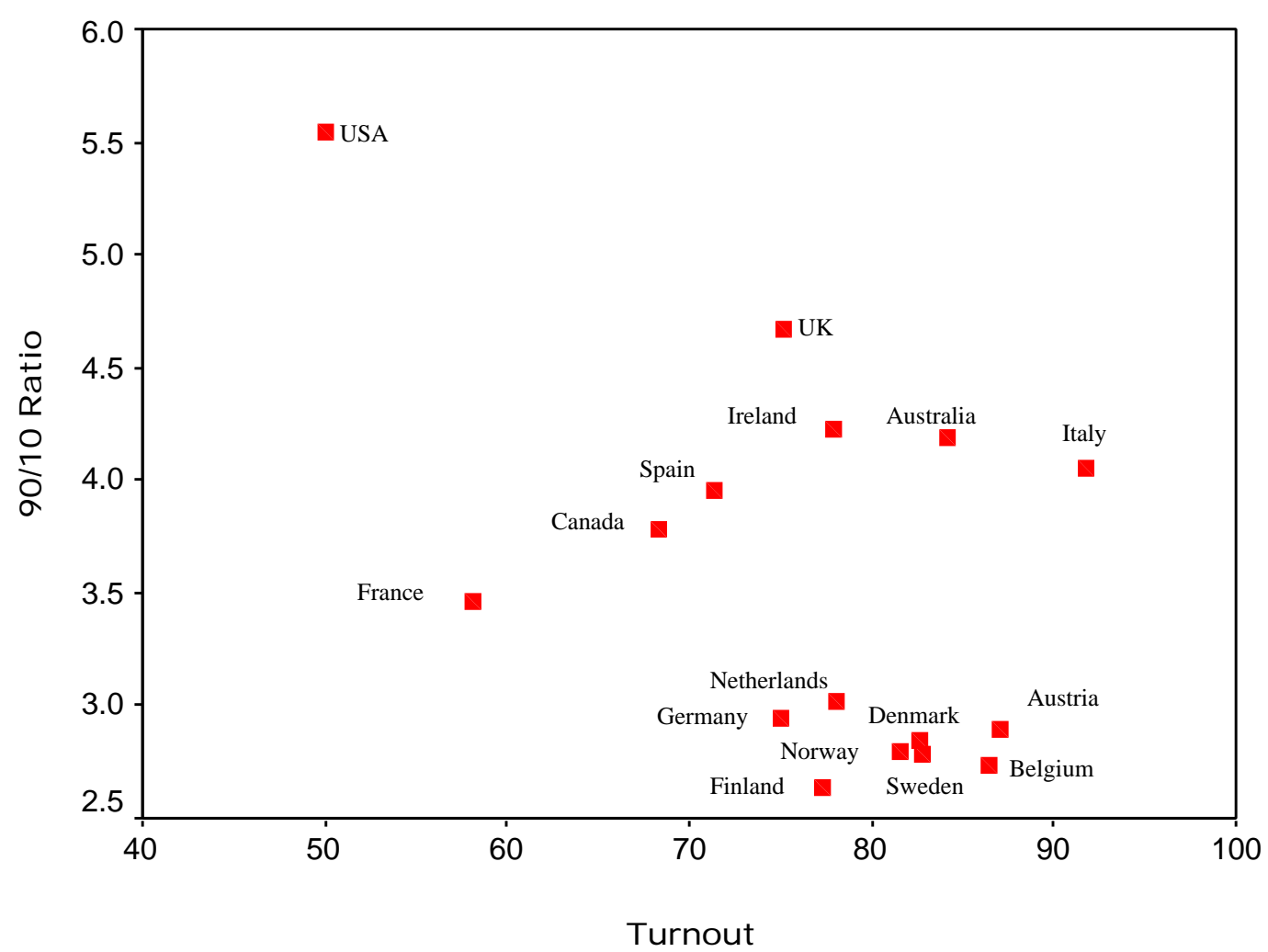

Figure 6: A Structural Equation Model of the Causes and Consequences of Cross-National Variance in Electoral Turnout

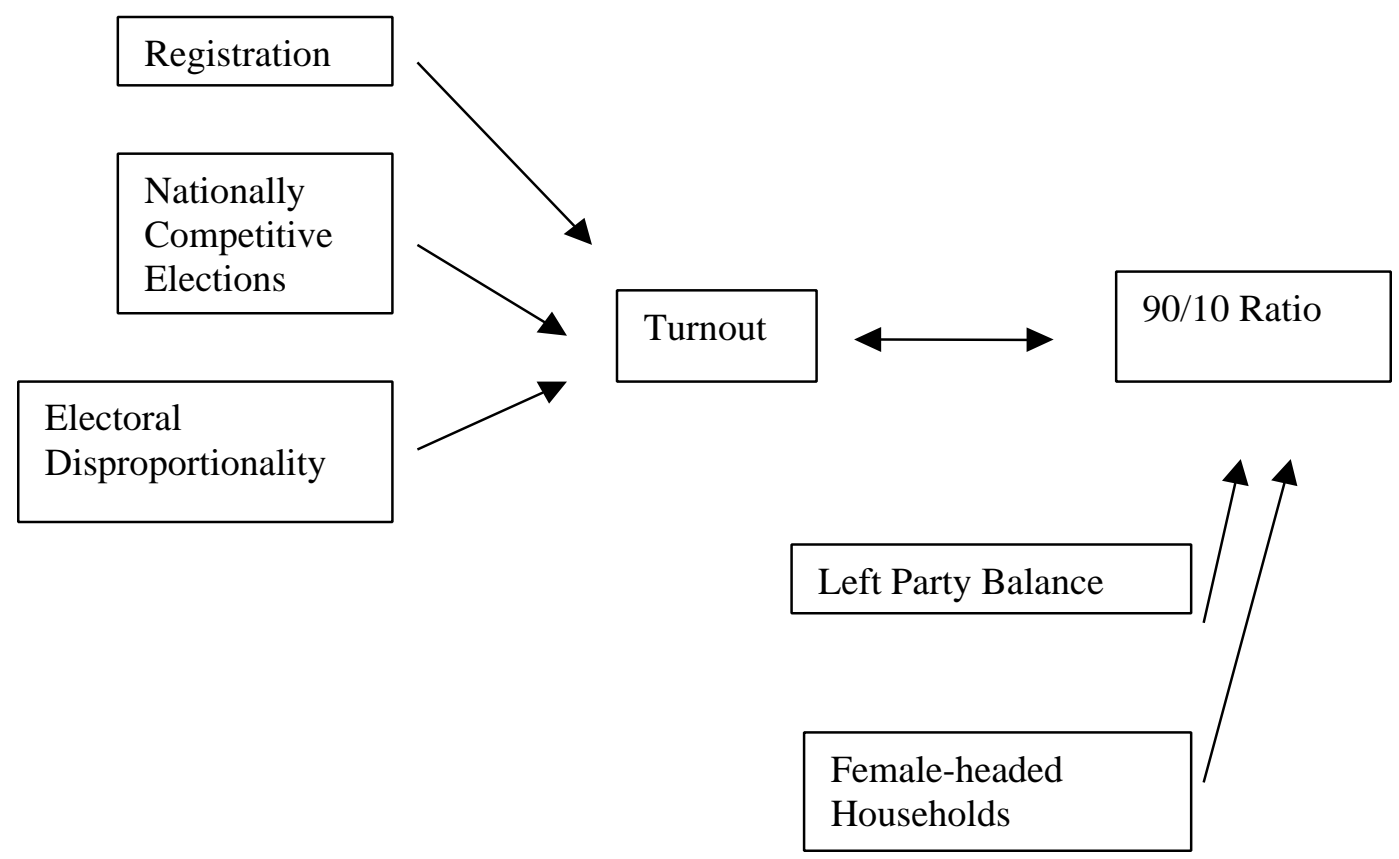


Vincent A. Mahler is Professor of Political Science at Loyola University Chicago. He is the author of Dependency Approaches to International Political Economy (Columbia University Press) and of articles in International Organization, The American Political Science Review, Comparative Political Studies, Comparative Politics, Polity, Review of International Political Economy, and other journals and edited collections. 